\title{
Solutions to a model with Neumann boundary conditions for sea-ice growth
}

\author{
Yangxin Tang ${ }^{1}$ and Lin Zheng ${ }^{1}$ \\ ${ }^{1}$ Anhui University of Finance and Economics
}

October 18, 2021

\begin{abstract}
We continue to study an initial boundary value problems to a model describing the evolution in time of diffusive phase interfaces in sea-ice growth. In a previous paper global existence and the long-time of behavior of weak solutions in one space was studied under Dirichlet boundary conditions. Here we show that the global existence of weak solutions and the long-time behavior are also studied under Neumann boundary condition. In this paper we study in space dimension lower than or equal to $\$ 3 \$$.
\end{abstract}

\section{Hosted file}

file2.pdf available at https://authorea.com/users/404334/articles/542175-solutions-to-amodel-with-neumann-boundary-conditions-for-sea-ice-growth 